\title{
$\beta$-Carboline Silver Compound Binding Studies with Human Serum Albumin: A Comprehensive Multispectroscopic Analysis and Molecular Modeling Study
}

\author{
Ali Alsalme $\mathbb{D}^{1},{ }^{1}$ Rais Ahmad Khan $\left(\mathbb{D},{ }^{1}\right.$ Arwa M. Alkathiri, ${ }^{1}$ Mohd. Sajid Ali $\mathbb{D},{ }^{2}$ \\ Sartaj Tabassum, ${ }^{2}$ Mohammed Jaafar, ${ }^{1}$ and Hamad A. Al-Lohedan $\mathbb{D D}^{2}$ \\ ${ }^{1}$ Department of Chemistry, College of Science, King Saud University, P.O. Box 2455, Riyadh 11451, Saudi Arabia \\ ${ }^{2}$ Surfactant Research Chair, Department of Chemistry, College of Science, King Saud University, P.O. Box 2455, Riyadh 11451, \\ Saudi Arabia
}

Correspondence should be addressed to Ali Alsalme; aalsalme@ksu.edu.sa and Rais Ahmad Khan; raischem@gmail.com

Received 2 October 2017; Revised 3 January 2018; Accepted 31 January 2018; Published 25 March 2018

Academic Editor: Viktor Brabec

Copyright (c) 2018 Ali Alsalme et al. This is an open access article distributed under the Creative Commons Attribution License, which permits unrestricted use, distribution, and reproduction in any medium, provided the original work is properly cited.

$\beta$-Carbolines $(\beta \mathrm{Cs})$ belong to the naturally occurring alkaloid family, derived from $9 \mathrm{H}$-pyrido[3,4-b]indole, also known as norharmane (Hnor). Knowing the importance of the $\beta$ Cs alkaloid family in biological processes, a comprehensive binding study is reported of four $\mathrm{Ag}(\mathrm{I})$ compounds containing the ligand Hnor and having different counteranions, namely, $\mathrm{NO}_{3}^{-}, \mathrm{ClO}_{4}^{-}, \mathrm{BF}_{4}^{-}$, and $\mathrm{PF}_{6}{ }^{-}$, with human serum albumin (HSA) as a model protein. Different approaches like UV-visible, fluorescence spectroscopy, circular dichroism (CD), and molecular docking studies have been used for this purpose. The fluorescence results establish that the phenomenon of binding of $\mathrm{Ag}(\mathrm{Hnor})$ complexes to HSA can be deduced from the static quenching mechanism. The results showed a significant binding propensity of the used $\mathrm{Ag}(\mathrm{I})$ compounds towards HSA. The role of the counteranion on the binding of $\mathrm{Ag}(\mathrm{I})$ compounds to HSA appeared to be remarkable. Compounds with $\left(\mathrm{ClO}_{4}{ }^{-}\right)$and $\left(\mathrm{NO}_{3}{ }^{-}\right)$were found to have the most efficient binding towards HSA as compared to $\mathrm{BF}_{4}{ }^{-}$and $\mathrm{PF}_{6}{ }^{-}$. Circular dichroism (CD) studies made clear that conformational changes in the secondary structure of HSA were induced by the presence of $\operatorname{Ag}(\mathrm{I})$ compounds. Also, the $\alpha$-helical structure of HSA was found to get transformed into a $\beta$-sheeted structure. Interestingly, $\left(\mathrm{ClO}_{4}^{-}\right)$and $\left(\mathrm{NO}_{3}{ }^{-}\right)$compounds were found to induce most substantial changes in the secondary structure of HSA. The outcome of this study may contribute to understanding the propensity of proteins involved in neurological diseases (such as Alzheimer's and Parkinson's diseases) to undergo a similar transition in the presence of $\mathrm{Ag}-\beta$-carboline compounds.

\section{Introduction}

The history of silver applications started from its use in coins and jewelry. Women loved to decorate themselves with various trinkets of silver, but it is less well known that this metal can be an excellent metallotherapeutic agent. In the human body, silver (Ag) is not acting as an endogenous metal and exhibits relatively low toxicity. $\mathrm{Ag}(\mathrm{I})$ coordination compounds with a variety of ligands having nitrogen, phosphorus, and/or sulfur donor atoms have large applications in medicinal and analytical chemistry $[1,2]$. Specifically, the antibacterial and antifungal actions of $\mathrm{Ag}(\mathrm{I})$ compounds are well known [3-7]. The properties of silver compounds, like aqueous solubility, light stability, and biological activity, can be modified by varying the number and types of organic ligands [1-7]. Furthermore, in the more recent past, $\mathrm{Ag}(\mathrm{I})$ compounds have also been reported to display antitumor activity and have shown activities comparable to the clinical chemotherapeutic drug (cisplatin) [8-11].

Human serum albumin (HSA) is responsible for about $60 \%$ of the plasma protein in humans and is accountable for nearly $80 \%$ of the osmotic pressure of the blood, and it plays a prominent role in drug disposition and efficacy [12]. Various drugs bind reversibly to albumin and other serum components, which thereby function as carriers [13]. Serum albumin is known to increase the solubility of many drugs in 
plasma and modulates their delivery to cells in vivo and in vitro [14-16]. Hence, it is relevant to study the interactions of drug candidates with this protein.

Norharmane, 9H-pyrido[3,4-b]indole, is a rather unconventional ligand, belonging to an alkaloid family called $\beta$-carbolines $(\beta \mathrm{Cs})$. The molecule can act as a coordinating ligand, an $\mathrm{H}$-bonding donor/acceptor, and may also act on $\pi-\pi$ stacking; all these properties may act in synergy. A schematic chemical structure of norharmane is included in Figure 1.

$\beta$-Carbolines are present in many plants, arthropods, and insects. Endogenously, these alkaloids are synthesized by tryptophan or tryptophan-like indoleamines and also found in urine, plasma, platelets $(\sim 0.1 \mathrm{nM})$, in the case of mammals. Interestingly, after alcohol intake and smoking, $\beta$-carboline concentrations are found to increase to $\sim 1.0 \mathrm{nM}$. It is also well known that some $\beta$-carboline derivates on photoexcitation induce chromosomal damages in mammal cells and may disarm viruses and bacteria [17]. Moreover, substituted aromatic $\beta$-carbolines may enter into the brain by crossing the blood-brain barrier (BBB) and may then be converted into methyl derivatives by specific enzymes, like methyltransferases. Some $\beta$-carbolines like 2,9-dimethyl$\beta$-carbolines have exhibited mitochondrial damage leading to neurotoxicity, while 9-methyl-harmine has a neuroprotective effect. $\beta$-Carboline compounds are also known to reduce the expression of phosphorylated forms of the socalled tau protein, potently at multiple Alzheimer's diseaserelated sites [17-20].

In a previous study, some of us have shown that compounds of composition $\left[\mathrm{Ag}(\mathrm{Hnor})_{2}\right]$ (anion) display significant anticancer activity for the anions, namely, $\mathrm{NO}_{3}{ }^{-}, \mathrm{ClO}_{4}{ }^{-}$, $\mathrm{BF}_{4}^{-}$, and $\mathrm{PF}_{6}^{-}$, with the $\mathrm{ClO}_{4}^{-}$compound being even comparable to cisplatin in two different cancer cell lines [21]. To explore the possible molecular mechanism of action, we have decided to undertake a study of protein binding of the four silver compounds (1-4) with Hnor varying the ionic sphere by changing the counteranions, namely, using $\mathrm{NO}_{3}{ }^{-}$, $\mathrm{ClO}_{4}^{-}, \mathrm{BF}_{4}{ }^{-}$, and $\mathrm{PF}_{6}$. HSA has been selected as a model for the protein binding studies. As spectroscopic techniques, UV-visible, fluorescence spectroscopy, and circular dichroism (CD) techniques have been chosen. Finally, the interactions of the $\operatorname{Ag}(\mathrm{I})$ compounds with the protein were studied using molecular modeling.

\section{Experimental Section}

2.1. Starting Materials and Syntheses. $\mathrm{AgNO}_{3}, \mathrm{AgClO}_{4}$, $\mathrm{AgBF}_{4}, \mathrm{AgPF}_{6}, \mathrm{DL}$-tryptophan, and formaldehyde were purchased from Sigma-Aldrich. Human serum albumin (HSA; $\geq 99 \%$, Sigma, USA) was essentially fatty-acid free and globulin free, purchased from Sigma, and used as received. We have synthesized the four $\mathrm{Ag}(\mathrm{I})$ compounds as described in before [21]. Other standard laboratory chemicals were used as available. Studies of protein folding have mainly been carried out in buffered dilute aqueous solutions to avoid loss of protein to the aggregation phenomenon. Stock solutions of HSA $(300 \mu \mathrm{M})$ and $\operatorname{Ag}(\mathrm{I})$ compounds were prepared in a mixture of dimethyl sulfoxide (5\%) DMSO and 95\%

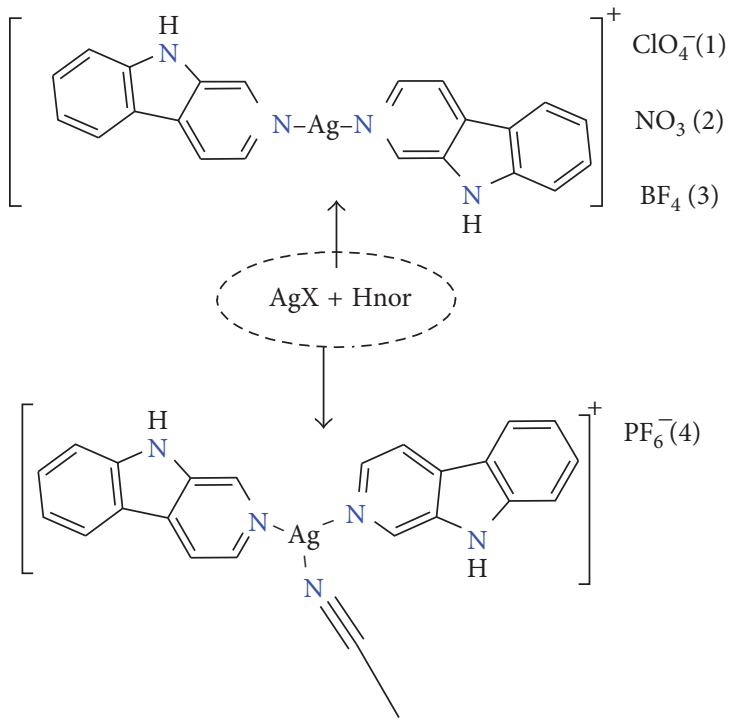

Figure 1: The structures of the ligand 9H-pyrido[3,4-b]indole (Hnor) and the four used $\mathrm{Ag}(\mathrm{I})$ compounds.

phosphate buffer $(20 \mathrm{mM})$ of $\mathrm{pH} 7.4$ (i.e., well above the isoelectric point of $\mathrm{HSA}, \mathrm{pH} 4.7$; hence, the protein possesses a net negative charge at this $\mathrm{pH}$ ). Conductivity in solution was studied by using an Accumet AB30 Fisher Scientific conductometer at room temperature in $\mathrm{MeOH}$ solution of the compounds.

2.2. Protein Binding Studies. The samples of HSA were prepared in $20 \mathrm{mM}$ phosphate buffer ( $\mathrm{pH}$ 7.4), whereas silver complexes $(1 \mathrm{mM})$ stock solution were prepared in DMSO and further diluted in $20 \mathrm{mM}$ phosphate buffer to reach the desired concentration. In all the samples, the final concentration of DMSO was not more than $1 \%$. The concentration of HSA was determined using the Beer-Lambert law with the molar extinction coefficient of $36500 \mathrm{M}^{-1} \cdot \mathrm{cm}^{-1}$ at $280 \mathrm{~nm}$. To study structural changes in HSA by the addition of $[\mathrm{Ag}(\mathrm{I})$ (Hnor $\left.)_{2}\right]$ (anion) compounds, the UV absorption spectra were measured, by variation of the concentration of the $[\mathrm{Ag}(\mathrm{I})$ (Hnor $\left.)_{2}\right]$ (anion) compounds, while keeping the concentration of HSA constant. UV absorption spectra, from $240 \mathrm{~nm}$ to $320 \mathrm{~nm}$, were recorded on a Perkin-Elmer Lambda 45 spectrophotometer at $25^{\circ} \mathrm{C}$. Quartz cuvettes of $1 \mathrm{~cm}$ path length were used for the measurements. Fluorescence measurements were performed on a Hitachi spectrofluorometer (Model F 7000) equipped with a PC. The fluorescence spectra were collected at $25^{\circ} \mathrm{C}$ with a path length cell of $1 \mathrm{~cm}$. The slit width used was $5 \mathrm{~nm}$ with a protein concentration of $5 \mu \mathrm{M}$. The used excitation wavelength for the protein was $295 \mathrm{~nm}$.

$\mathrm{CD}$ measurements were carried out on a Jasco spectropolarimeter (Model J-815) equipped with a microcomputer. The instrument was calibrated with D-10-camphorsulfonic acid. All the $\mathrm{CD}$ measurements were performed at $25^{\circ} \mathrm{C}$ with a thermostatically controlled cell holder, attached to a Neslab RTE-110 water bath with an accuracy of $\pm 0.1^{\circ} \mathrm{C}$. Spectra were collected with a scan speed of $0.2 \mathrm{~nm} / \mathrm{min}$ and a response time of $1 \mathrm{~s}$. Each spectrum was taken as the average of three scans. 
The far-UV CD spectra were measured at a protein concentration of $20 \mu \mathrm{M}$ at a path length of $1 \mathrm{~cm}$.

All the spectra were recorded after equilibration of the reaction mixture for $5 \mathrm{~min}$.

2.3. Molecular Docking. The rigid molecular docking studies were performed by using HEX 8.0.0 software [22], which is an interactive molecular graphics program for calculating and displaying possible docking modes of protein. The Hex 8.0.0 performs protein docking using spherical polar Fourier correlations [23]. Hex 8.0.0 necessitates the ligand and the receptor as input in PDB format. The parameters used for docking include the following: correlation type: shape only; FFT mode: 3D; grid dimension: 0.6 ; receptor range: 180 ; ligand range: 180; twist range: 360; and distance range: 40 . The coordinates of compounds $\mathbf{1}$ and $\mathbf{2}$ were taken from its crystal structure as a .cif file and were converted to the PDB format using Mercury software. The crystal structure of the human serum albumin (PDB ID: 1h9z) was downloaded from the protein data bank (http://www.rcsb.org./pdb). Visualization of minimum energy favorable docked poses has been performed using Discovery Studio 4.1 [24] and PyMOL [25].

\section{Results and Discussion}

3.1. General Observations and Synthesis. Synthesis of the four $\mathrm{Ag}(\mathrm{I})$ compounds, namely, $\left[\mathrm{Ag}(\mathrm{Hnor})_{2}\right]\left(\mathrm{ClO}_{4}\right)$ (1), $\left[\mathrm{Ag}(\mathrm{Hnor})_{2}\right]\left(\mathrm{NO}_{3}\right)(2),\left[\mathrm{Ag}(\mathrm{Hnor})_{2}(\mathrm{MeCN})\right]\left(\mathrm{PF}_{6}\right)(3)$, and $\left[\mathrm{Ag}(\mathrm{Hnor})_{2}\right]\left(\mathrm{BF}_{4}\right)(4)$, were done by dissolving the starting $\mathrm{Ag}$ salt and Hnor in acetonitrile (ratio 1:2); they were characterized according to the procedures reported by some of us previously [21]. Conductivity studies in $\mathrm{MeOH}$ solution (1-5 mM) have shown that the compounds behave as $1: 1$ electrolytes. Given the known kinetic lability of $\mathrm{Ag}(\mathrm{I})$, it is assumed that the Hnor ligand may dissociate from and associate with the Ag ion, in solution, but on average, they are largely coordinated. The schematic structures of the ligand and the used $\mathrm{Ag}(\mathrm{I})$ compounds are depicted in Figure 1.

3.2. HSA Binding Studies. The interaction between the small bioactive molecules and protein receptors is a fundamental step in the drug discovery process. Obtaining a thorough idea of the interaction of the protein with chemical entities plays a vital role in the etiology of several diseases. The protein-drug intermediate products involved in governing various biochemical phenomena in both normal and diseased cells are known to play a significant role in metabolizing therapeutic compounds and their transport [26, 27].

3.2.1. UV Absorption Studies. The binding propensity of the drug candidate with the biomolecule was first studied by using the UV technique. The cumulative absorption of three aromatic amino acid residues gives rise to an absorption peak at $280 \mathrm{~nm}$ for human serum albumins (HSA) [28]. Figure 2 displays the UV absorption spectra of HSA in the absence and presence of $\left[\mathrm{Ag}(\mathrm{I})(\mathrm{Hnor})_{2}\right] \mathrm{ClO}_{4}$. The behavior

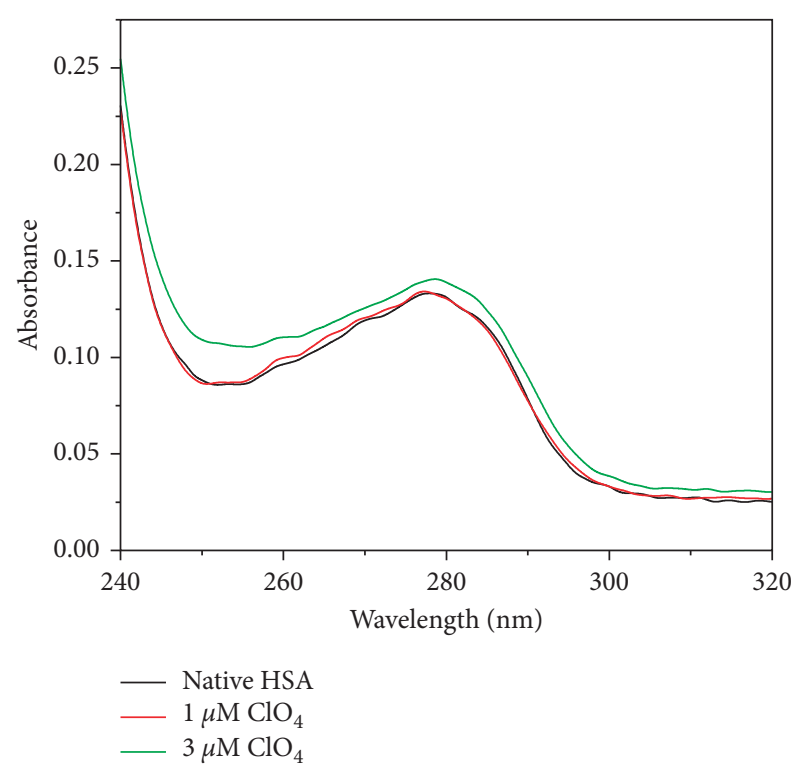

Figure 2: UV absorption difference spectra of HSA $(5 \mu \mathrm{M})$. These spectra represent the effect of compound 1 at $1 \mu \mathrm{M}$ and $3 \mu \mathrm{M}$ concentrations. (The difference spectrum was obtained by the HSA-Ag compound spectra minus Ag compound spectra).

of the other 3 compounds (compounds 2-4) is quite similar, and these data are presented in Figure S1 (see Supplementary Materials).

With the concomitant increase in concentration of $\mathrm{Ag}(\mathrm{I})$ compounds, the absorbance of HSA increased, and shifts toward longer wavelengths were observed; the $\mathrm{Ag}(\mathrm{I}) \mathrm{com}$ pounds give a definite pattern of the UV-Vis spectrum with weak absorbance at a higher concentration between 295 and $320 \mathrm{~nm}$, ascribed to the ligand "Hnor." The profound enhancement of UV absorbance (hyperchromism) with a redshift (bathochromic effect) of $7 \mathrm{~nm}(1), 5 \mathrm{~nm}(2), 5 \mathrm{~nm}$ (3), and $6 \mathrm{~nm}(4)$ in the spectra is suggestive of the formation of adducts/intermediates between the $\mathrm{Ag}(\mathrm{I})$ compounds and HSA. HSA is known to act as an important extracellular antioxidant, and this antioxidant property resides in one free cysteine-derived redox-active thiol (-SH) group (i.e., Cys34), which can occur in either reduced or oxidized form. $\mathrm{Ag}(\mathrm{I})$ being a soft Lewis acid, its compounds are known to have a high affinity towards sulfur-ligand atoms and moderate affinity towards nitrogen donor atoms. However, binding of $\mathrm{Ag}(\mathrm{I})$ towards methionine (Met)/histidine(His) residues and disulfide bridges, and nitrogen atoms, such as deprotonated peptide nitrogen, imine, and indole nitrogen, also cannot be ruled out completely $[29,30]$. However, the compounds $\mathbf{1 - 4}$ are quite stable in the solution.

The difference spectra of HSA have confirmed that the conformational changes to HSA are due to binding of the $\mathrm{Ag}$ (I) compounds (Figure 3 and also Figure S2 in Supplementary Materials). Nevertheless, the variation in binding extent/mode exhibited by the spectra of the compounds to HSA may be associated with the effect of the counteranions. The anions may have facilitated the microenvironmental changes of protein and exposed the targeted site of a subdomain of protein to assist or enhance the selectivity of the 


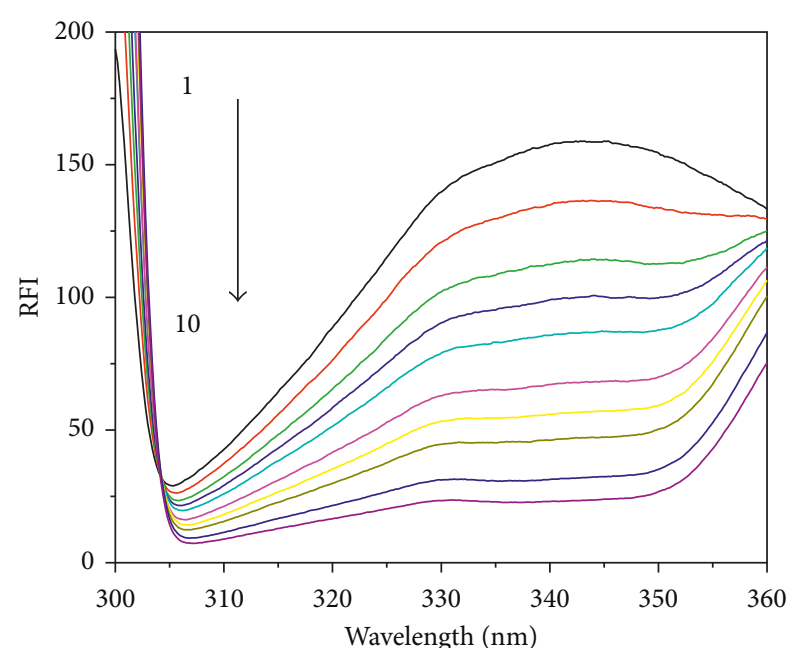

Figure 3: Fluorescence emission spectra of HSA $(5 \mu \mathrm{M})$ in the presence of various concentrations of $\left[\mathrm{Ag}(\mathrm{I})(\mathrm{Hnor})_{2}\right] \mathrm{ClO}_{4}$. Curves 1 to 10 correspond to compound concentrations of $0,0.5,1,1.5,2,3$, $4,5,7.5$, and $10 \mu \mathrm{M}$, respectively, when excited at $295 \mathrm{~nm}$.

metal center, that is, $\operatorname{Ag}(\mathrm{I})$. The effect of anions has been studied with the help of molecular docking to get further insight into their role. The possible role of anions has been discussed in computational studies section. However, the dissociation of the $\operatorname{Ag}(\mathrm{I})$ compound is a matter of main concern that we have also studied and found quite stable complex association of $\mathrm{Ag}(\mathrm{I})-\mathrm{Hnor}$. Shen et al. [31] have studied the interaction of $\mathrm{Ag}^{+}$alone with HSA. When we compared these results of $\mathrm{Ag}$ compounds with $\mathrm{Ag}^{+}$alone, silver compounds exhibited significantly worthy binding propensity compared to the $\mathrm{Ag}^{+}$alone. In the next stage, with the aim to gain more information about the mode of binding of the $\mathrm{Ag}(\mathrm{I})$ compounds with HSA, solution fluorescence studies were carried out.

3.2.2. Luminescence Studies. The interaction between metal compounds and proteins has been widely investigated by using fluorescence spectroscopies [32-34]. The luminescence response of HSA, upon addition of different concentrations of Ag(I) compounds, was studied in $20 \mathrm{mM}$ phosphate buffer by using an emission titration experiment. Preliminary luminescence studies of the four starting Ag compounds 1-4 have been reported earlier by some of us [21]. The excitation at $290 \mathrm{~nm}$ for all four compound results in a strong luminescence band at around $370 \mathrm{~nm}$. The fluorescence studies of the ligand "Hnor" as well as the free silver salt, " $\mathrm{AgNO}_{3}$," were also studied under the same conditions to compare the effect of separate entities with a combination of the two. Upon excitation at $295 \mathrm{~nm}$, fluorescence intensity around $340 \mathrm{~nm}$ is known to reflect the changes of the tryptophan residue microenvironment [35]. Encouragingly, the luminescence of HSA was found substantially decreased in the presence of increasing concentrations of $\left[\mathrm{Ag}(\mathrm{I})(\mathrm{Hnor})_{2}\right] \mathrm{ClO}_{4}$, as depicted in Figure 4. In Figure S3, similar data are presented for compounds $\mathbf{2 - 4}$, with only marginal differences upon anion variation.

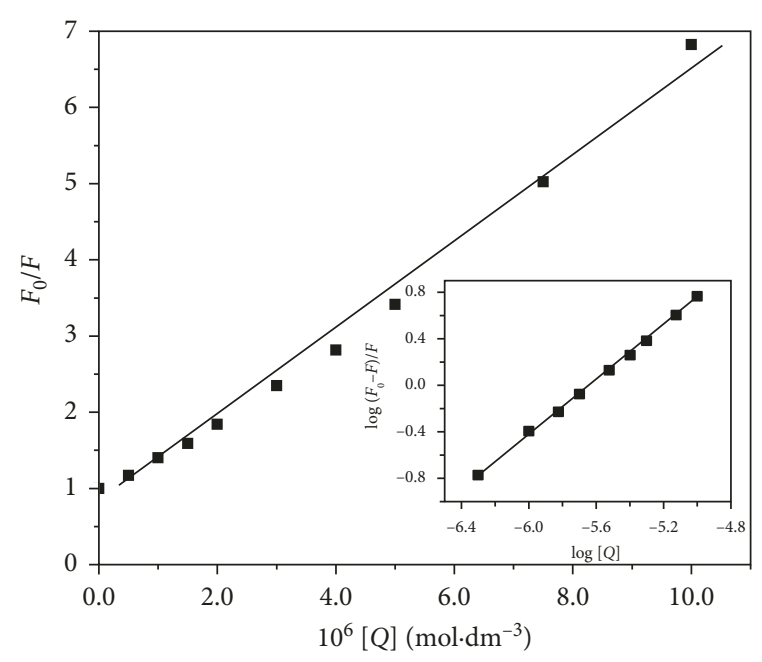

FIgURE 4: The Stern-Volmer plot of HSA fluorescence quenching by $\left[\mathrm{Ag}(\mathrm{I})(\text { Hnor })_{2}\right] \mathrm{ClO}_{4}$ at $295 \mathrm{~nm}$. Inset: plot of $\log \left(F_{0}-F\right) / F$ as a function of $\log$ [complex].

A gradual decrease in the luminescence of HSA was observed upon increasing concentration of $\mathrm{Ag}(\mathrm{I})$ compounds showed significant redshift at the maximal emission wavelength of tyrosine(Tyr) and tryptophan(Trp) residues of $7 \mathrm{~nm}(1), 5 \mathrm{~nm}(2), 4 \mathrm{~nm}(3)$, and $4 \mathrm{~nm}(4)$, which indicates the altered conformation of the HSA by decrease in the polarity around Tyr and Trp residues and increase in hydrophobicity. The continuous, gradual addition of $\mathrm{Ag}(\mathrm{I})$ compounds resulted in further decreases in the fluorescence intensity of HSA, which again is indicative of a strong interaction between the $\operatorname{Ag}(\mathrm{I})$ compounds and HSA. The factors linked to quenching of the fluorescence can be associated with, for example, excited-state reaction, energy transfer, molecular rearrangements, collisional quenching, and/or ground-state compound formation [36, 37]. Therefore, the consequence of these molecular interactions enforcing towards the static quenching that comprises the establishment of a ground state adduct between the fluorophore and the quencher. The involvement of static quenching in the binding process can be determined with the help of analyzed values of bimolecular quenching constant $\left(K_{\mathrm{q}}\right)$. A value of $K_{\mathrm{q}}$ higher than $2.0 \times 10^{10} \mathrm{M}^{-1} \cdot \mathrm{s}^{-1}$ reflects the quenching to be static [38-40].

The interaction of the Ag compounds with HSA was quantified; the Stern-Volmer equation has been employed [41]:

$$
\frac{F_{0}}{F}=1+K_{\mathrm{SV}}[Q]=1+K_{\mathrm{q}} \tau_{0}[Q],
$$

where $F_{0}$ and $F$ are the steady-state fluorescence intensities in the absence and presence of quencher at $340 \mathrm{~nm}$, respectively. $K_{\mathrm{sv}}$ is the Stern-Volmer quenching constant, $K_{\mathrm{q}}$ stands for bimolecular quenching constant, $\tau_{0}$ is the lifetime of the fluorophore in the absence of quencher, and $[Q]$ is the concentration of quencher (i.e., the $\mathrm{Ag}$ compound). By calculating the quenching rate constants, $K_{\mathrm{q}}$, one can distinguish between the static quenching and the dynamic quenching, and this was evaluated by using the following equation: 


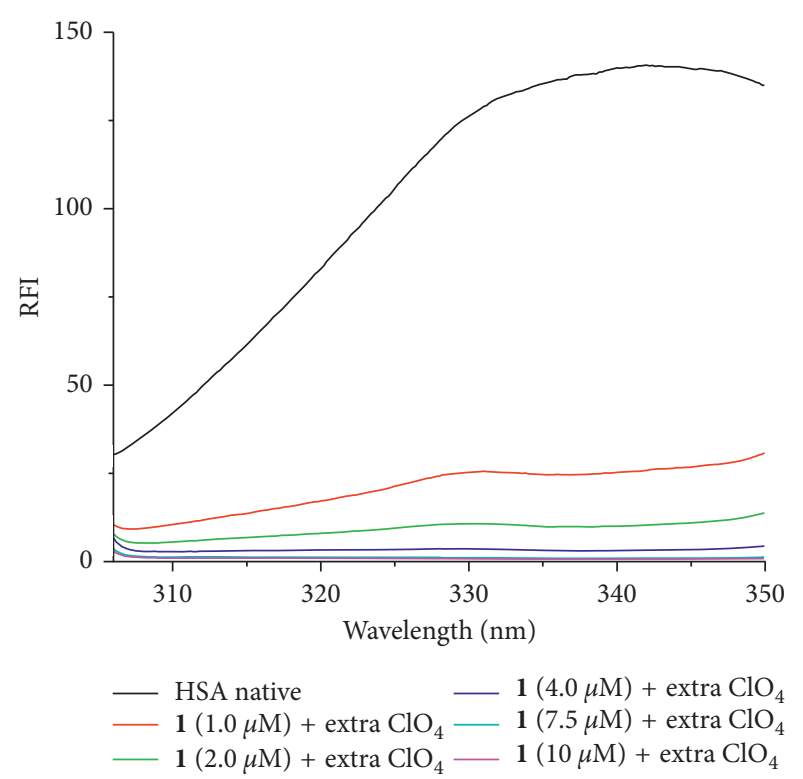

(a)

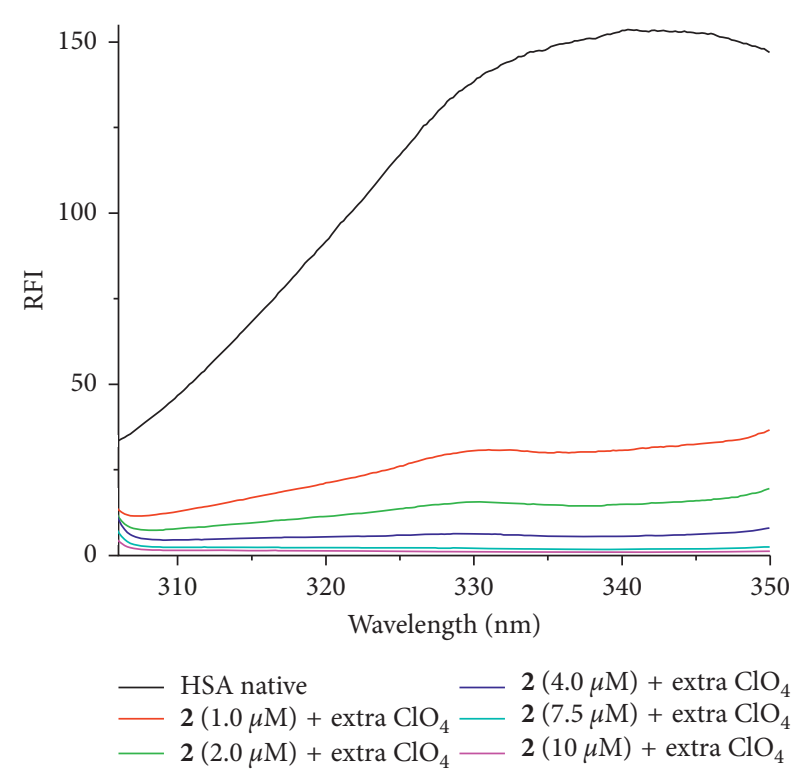

(b)

FIgURe 5: Fluorescence emission spectra of HSA $(5 \mu \mathrm{M})$ in the presence of various concentrations of (a) $\left[\mathrm{Ag}(\mathrm{I})\left(\mathrm{Hnor}_{2}\right] \mathrm{ClO}_{4} \mathrm{compound}\right.$ $1+$ extra $\mathrm{KClO}_{4}$, and (b) $\left[\mathrm{Ag}(\mathrm{I})(\mathrm{Hnor})_{2}\right] \mathrm{NO}_{3}$ compound $2+$ extra $\mathrm{KClO}_{4}$ corresponding to compound concentrations of 1.0, 2.0, 4.0, 7.5, and $10 \mu \mathrm{M}$, respectively, when excited at $295 \mathrm{~nm}$.

TABle 1: Stern-Volmer quenching constants and bimolecular quenching rate constant for the interaction of HSA with four Ag(I) Hnor compounds.

\begin{tabular}{lccccc}
\hline Complex & $K_{\mathrm{SV}}\left(10^{5}\right)\left(\mathrm{M}^{-1}\right)$ & $K_{\mathrm{q}}\left(10^{12}\right)\left(\mathrm{M}^{-1} \cdot \mathrm{s}^{-1}\right)$ & $K\left(10^{6}\right)\left(\mathrm{M}^{-1}\right)$ & $n$ & $\left.\Delta G(\mathrm{~kJ} \mathrm{~mol})^{-1}\right)$ \\
\hline $\mathbf{1}\left(\mathrm{ClO}_{4}^{-}\right)$ & 5.37 & 53.7 & 3.74 & 3.64 & 1.1 \\
$\mathbf{2}\left(\mathrm{NO}_{3}^{-}\right)$ & 5.34 & 53.4 & 0.55 & 1.2 & -37.50 \\
$\mathbf{3}\left(\mathrm{PF}_{6}^{-}\right)$ & 4.53 & 45.3 & 1.14 & 1.1 & -32.73 \\
$\mathbf{4}\left(\mathrm{BF}_{4}^{-}\right)$ & 3.97 & 39.7 & 0.33 & 1.0 & -34.55 \\
$\mathrm{Hnor}^{-}$ & 2.95 & 29.5 & 1.94 & -31.40 \\
$\mathrm{AgNO}_{3}$ & 3.10 & 31.0 & & -35.88 \\
\hline
\end{tabular}

$$
K_{\mathrm{q}}=\frac{K_{\mathrm{SV}}}{\tau_{0}} .
$$

The value of tau(zero), $\tau_{0}$, for biopolymers is known to be $10^{-8}$ s. [33] The Stern-Volmer quenching constant $\left(K_{\mathrm{sv}}\right)$ for the fluorometric titration of the $\mathrm{Ag}(\mathrm{I})$ compounds into HSA solution was calculated from the linear relationship between $F_{0} / F$ and $\left[\mathrm{Ag}(\mathrm{I})(\mathrm{Hnor})_{2}\right] \mathrm{ClO}_{4}$ (Figure 5) and enlisted in Table 1. In Figure S4, similar data are presented for compounds 2-4, confirming the above observations.

Thus, these data ascertain the static quenching in the interaction of $\mathrm{Ag}(\mathrm{I})$ compounds with HSA, by the calculated value of $K_{\mathrm{q}}$. The equilibrium between free and bound molecules, when small molecules bind independently to a set of similar sites on a macromolecule, was ascertained by a modified Stern-Volmer equation [42]:

$$
\log \frac{F_{0}-F}{F}=\log K+n \log [Q]
$$

where $K$ and $n$ are the binding constant and the number of binding sites, respectively. A plot of $\log \left(F_{0}-F / F\right)$ versus $\log [Q]$ was used to determine the value of $K$ and $n$ (inset in Figure 5). Several forces, like electrostatic, hydrogen bonds, weak van der Waals, hydrophobic, and steric contacts, can be thought of being responsible for the interaction between the albumin and Ag compounds. The value of the binding constant, $K$, was used to calculate the standard free energy change $\Delta G^{\circ}$ of the binding of the ligand to the HSA, by using the relationship [42]:

$$
\Delta G=-2.303 \mathrm{RT} \log K .
$$

The values of $K, n$, and $\Delta G$ (binding) are presented in Table 1 . All estimated values of $n$ are approximately 1 , indicating the existence of just one major binding site in HSA for the present $\operatorname{Ag}(\mathrm{I})$ compounds.

The extent of interaction of $\mathrm{Ag}(\mathrm{I})$ compounds with HSA was found in the order $1\left(\mathrm{ClO}_{4}^{-}\right)>2\left(\mathrm{NO}_{3}^{-}\right)>\mathbf{4}\left(\mathrm{BF}_{4}^{-}\right)>3$ $\left(\mathrm{PF}_{6}{ }^{-}\right)$, which can be associated with the differences in the effect of counteranions. Thus, compounds $\mathbf{1}\left(\mathrm{ClO}_{4}{ }^{-}\right)$and 2 $\left(\mathrm{NO}_{3}{ }^{-}\right)$exhibit significantly higher binding affinities towards HSA, compared to other two compounds.

Since it is known that HSA is a monomeric, three-domain, allosteric protein with only one free cysteine, Cys34, the Ag(I) ion could selectively bind at this site because it has a strong 
preference for S-donor atoms. Also, it can be assumed that the counteranions have facilitated the microenvironmental changes and may have contributed to the exposure of Cys34 from the subdomain of HSA and facilitated that the sulfur atom of cysteine will coordinate to the $\mathrm{Ag}(\mathrm{I})$ center of the compounds. Nevertheless, the known affinity of $\mathrm{Ag}(\mathrm{I})$ for Met residues and disulfide bridges and nitrogen atoms of HSA coordination on such sites cannot be ignored completely. This hypothesis is supported by the observation that the extent of microenvironmental changes of the protein is much higher in the presence of additional $\mathrm{ClO}_{4}{ }^{-}$and $\mathrm{NO}_{3}{ }^{-}$anions (see below), and which agrees with the trend in their binding parameter (Table 1); thus, a more profound effect on the $\operatorname{Ag}(\mathrm{I})$ compound and its HSA interaction is observed.

3.3. Effects of Addition of Additional Anions. Given the fact that the highest anticancer activity and also the most substantial HSA interaction takes place in case of the perchlorate and nitrate salts, it was decided to add extra perchlorate (and also nitrate) for all cases and to study the effect on the binding affinity. So, we carried out two sets of experiments and studied the binding propensity of $\mathrm{Ag}(\mathrm{I})$ compounds with HSA. In one experiment, the extra $\mathrm{ClO}_{4}{ }^{-}$anion was added in a $1: 4$ ratio, compared to the Ag compound. In a second experiment, we used additional nitrate together with the $\mathrm{Ag}(\mathrm{I})$ compounds. Details are given in Figures 6 and 7, and the quite similar details for the other 3 compounds are presented in Figures S5 and S6 in Supplementary Materials.

To determine the role of only the anions (i.e., without $\mathrm{Ag}$ and Hnor), we also used $\mathrm{KClO}_{4}$ and $\mathrm{KNO}_{3}$ and studied their HSA binding by adding variable amounts of anions to the concentration maximum used in the experiments. We found that on the addition of $\mathrm{KClO}_{4}$ and $\mathrm{KNO}_{3}$ to HSA, only a negligible perturbance of the HSA structure has occurred. Hence, the effect of these anions $\left(\mathrm{ClO}_{4}{ }^{-}\right.$and $\left.\mathrm{KNO}_{3}{ }^{-}\right)$on HSA conformation can be neglected in comparison to the effect of $\mathrm{Ag}$ compounds and $\mathrm{Ag}$ compounds + additional anions on HSA conformation. When the extra anions + compounds were titrated, the results obtained did show an exponential increase in binding affinity of the $\mathrm{Ag}(\mathrm{I})$ compounds.

These findings can be attributed to the enhanced exposure of the cysteine sulfur atoms of HSA, most likely caused by the significant electrostatic effect of the additional anions. This behavior is indicative of the increased microenvironmental changes of the HSA, thereby allowing the more binding of the $\mathrm{Ag}(\mathrm{I})$ center to coordinate to the HSA binding site.

The binding strength was evaluated by calculating the Stern-Volmer constant $\left(K_{\mathrm{sv}}\right)$, a number of the binding sites $(n)$ and Gibbs free energy $(\Delta G)$; (Table 2). It should be noted that the effect of $\mathrm{ClO}_{4}{ }^{-}$is quite high, whereas $\mathrm{NO}_{3}{ }^{-}$and $\mathrm{BF}_{4}{ }^{-}$ mutually exhibit a nearly similar level of effect, while the $\mathrm{PF}_{6}{ }^{-}$ anion comes at the end showing a smaller effect. However, no correlation with the size of these four anions is seen.

The effect of anions was also analyzed on the basis of binding constant $(K)$ to study the binding affinity. The binding constant's value exhibited a vibrant increase in the presence of extra anions in particular with $\mathrm{ClO}_{4}{ }^{-}$and $\mathrm{NO}_{3}{ }^{-}$

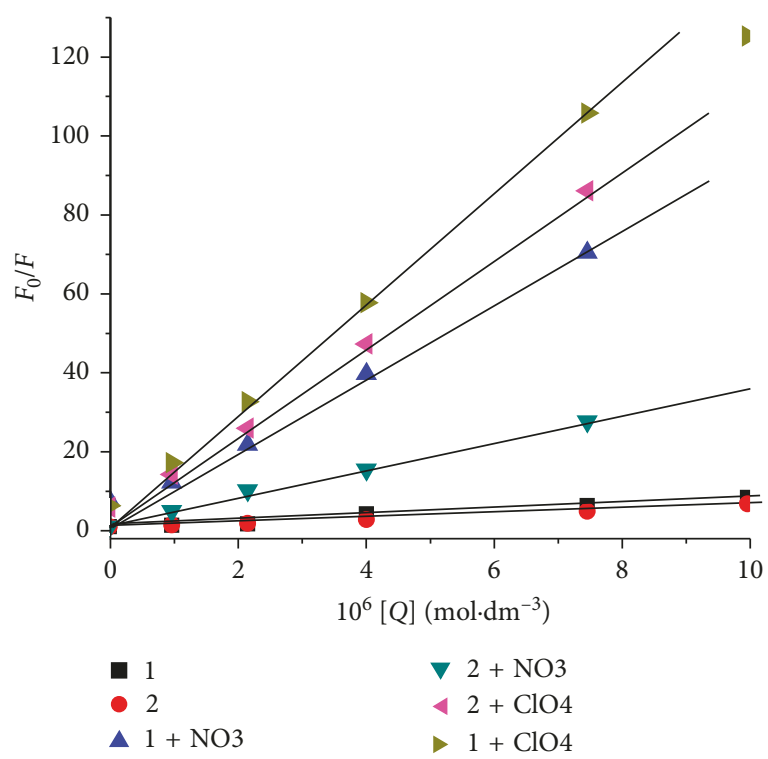

FIGURE 6: Stern-Volmer plot of HSA fluorescence quenching by (1) $\left[\mathrm{Ag}(\mathrm{I})(\text { Hnor })_{2}\right] \mathrm{ClO}_{4}$ and (2) $\left[\mathrm{Ag}(\mathrm{I})(\text { Hnor })_{2}\right] \mathrm{NO}_{3}$ with additional $\mathrm{KClO}_{4}$ and $\mathrm{KNO}_{3}$ at $295 \mathrm{~nm}$.

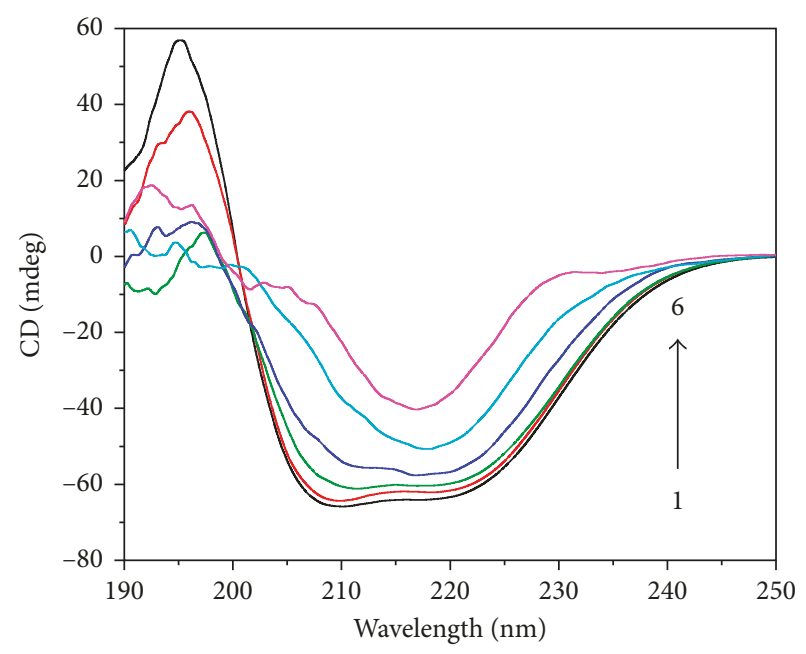

Figure 7: Far-UV CD spectra of HSA-compound system ( $\mathrm{HSA}=20 \mu \mathrm{M})$ in the presence of various concentrations of $[\mathrm{Ag}(\mathrm{I})$ (Hnor) $)_{2} \mathrm{ClO}_{4}$ complex. Curves from 1 to 6 correspond to compound concentrations of $0,20,40,60,80$, and $100 \mathrm{mM}$, respectively.

when compared with the results of complexes $\mathbf{1}$ and $\mathbf{2}$. In complexes 1 and 2, extra $\mathrm{ClO}_{4}{ }^{-}$showed significant increase in the binding affinity as compared to extra $\mathrm{NO}_{3}{ }^{-}$as evident from Table 2 ( $K$ values). This exponential increase of the magnitude of $10^{4}$ says a lot about the role of anions in the stronger binding affinity of the silver compounds with HSA. The order of binding of $\mathrm{Ag}(\mathrm{I})$ compounds with HSA upon extra anion addition was found to be $\mathbf{1}>\mathbf{2}>\mathbf{4}>\mathbf{3}$. Thus, it is evident that the number of the binding sites $(n)$ increases upon addition of extra anions.

3.4. Binding and Conformational Changes in Circular Dichroism. CD spectroscopy is an ideal technique for 
TABle 2: Parameters for the interaction of HSA with $\mathrm{Ag}(\mathrm{I})$ compounds with the addition of extra anion, namely, $\mathrm{ClO}_{4}{ }^{-}$and $\mathrm{NO}_{3}{ }^{-}$.

\begin{tabular}{|c|c|c|c|c|}
\hline Complex & $K_{\mathrm{SV}}\left(10^{7}\right)\left(\mathrm{M}^{-1}\right)$ & $K\left(10^{10}\right)\left(\mathrm{M}^{-1}\right)$ & $n$ & $\Delta G\left(\mathrm{~kJ} \mathrm{~mol}^{-1}\right)$ \\
\hline \multicolumn{5}{|l|}{ Set $A$} \\
\hline $\mathbf{1}\left(+\right.$ extra $\left.\mathrm{ClO}_{4}^{-}\right)$ & 2.21 & 17.2 & 1.77 & -64.12 \\
\hline $2\left(+\right.$ extra $\left.\mathrm{ClO}_{4}^{-}\right)$ & 1.29 & 6.05 & 1.58 & -57.48 \\
\hline $3\left(+\right.$ extra $\left.\mathrm{ClO}_{4}^{-}\right)$ & 0.84 & 0.46 & 1.55 & -55.13 \\
\hline $4\left(+\right.$ extra $\left.\mathrm{ClO}_{4}^{-}\right)$ & 1.85 & 1.19 & 1.69 & -61.52 \\
\hline \multicolumn{5}{|l|}{ Set $B$} \\
\hline $\mathbf{1}\left(+\right.$ extra $\left.\mathrm{NO}_{3}{ }^{-}\right)$ & 2.06 & 3.64 & 1.64 & -60.26 \\
\hline $2\left(+\right.$ extra $\left.\mathrm{NO}_{3}^{-}\right)$ & 1.24 & 0.66 & 1.53 & -56.05 \\
\hline $3\left(+\right.$ extra $\left.\mathrm{NO}_{3}^{-}\right)$ & 0.80 & 0.08 & 1.41 & -51.01 \\
\hline $4\left(+\operatorname{extra} \mathrm{NO}_{3}^{-}\right)$ & 1.38 & 0.38 & 1.48 & -54.67 \\
\hline
\end{tabular}

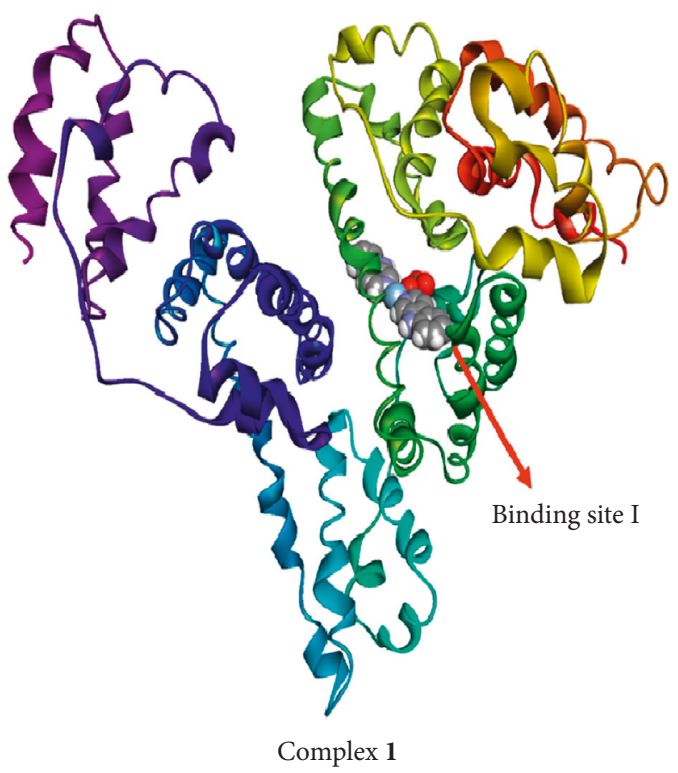

(a)

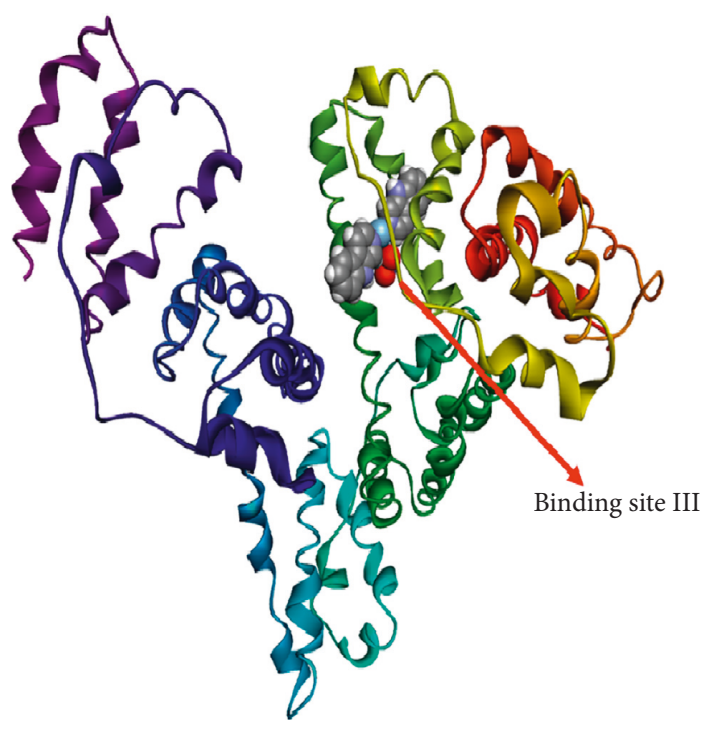

Complex 2

(b)

Figure 8: Binding of compounds (a) 1 and (b) 2 at different binding sites of HSA.

monitoring the conformational changes of proteins. As shown in Figure 8, the CD spectrum of free HSA (line 1) exhibits two negative bands at $208 \mathrm{~nm}$ and $222 \mathrm{~nm}$ in the ultraviolet region, attributed to $n-\pi^{*}$ transfer for the peptide bond, with a positive ellipticity at $193 \mathrm{~nm}$, which is the characteristic of an $\alpha$-helix structure of HSA [43]. CD often allows obtaining information for almost all secondary structural variants, such as $\alpha$-helices, $\beta$-sheets, $\beta$-turns, and random coil structures. All of these structures provide origins to bands of distinct forms and degrees in the far-UV region. Modifications of the ellipticity at $222 \mathrm{~nm}$ (-MRE222) are convenient methods for observing and quantifying changes in the $\alpha$-helical content [44]. CD spectra recorded in the presence and absence of various concentrations of $\mathrm{Ag}(\mathrm{I})$ compounds are presented in Figure 8. Similar CD curves for the other three compounds are shown in Figure S8, as they show comparable behavior.

The CD signal, expressed in millidegree, obtained over the wavelength range of $190-250 \mathrm{~nm}$, was converted to a mean residue ellipticity (MRE, $\theta$ ), using the following conversion:

$$
\operatorname{MRE}=\frac{\theta_{\text {obs }}(\text { mdeg })}{\left(10 \times n \times C_{p} \times l\right)},
$$

where $\theta_{\text {obs }}$ is the CD in millidegree, the number of amino acid residues (585) is given by $n$, " $l$ " is the path length $(\mathrm{cm})$, and $C_{p}$ is the molarity. The unit of MRE is $\mathrm{deg} \cdot \mathrm{cm}^{2} \cdot \mathrm{dmol}^{-1}$.

The $\alpha$-helix contents of free and combined HSA were calculated from the MRE value at $222 \mathrm{~nm}$, using the following equation $[43,45]$ :

$$
\% \alpha-\text { helix }=\left[\frac{\mathrm{MRE}_{222 \mathrm{~nm}}-2,340}{30,300}\right] \times 100 .
$$

With increasing concentrations of the $\mathrm{Ag}(\mathrm{I})$ compounds, the CD signal exhibits significant changes in ellipticity, and this change corroborates with the binding of the compounds with the HSA backbone (spectra 2-6, Figure 8). In fact with increasing concentration of the compounds the ellipticity decreases. However, at high concentration of silver compounds, a transition of the secondary structure (i.e., $\alpha$-helix to $\beta$-sheet) was observed. 
The results confirm that the compound binds to the amino acid residues of the primary polypeptide chain in HSA, which has distorted its hydrogen-bonding networks. Interestingly, the decrease in the $\alpha$-helical content is indicative of substantial microenvironmental changes of the polypeptide chains of HSA, which increased the exposure of some hydrophobic regions that were previously submerged. The microenvironmental changes of the protein were found more pronounced in the case of $\mathbf{1}\left(\mathrm{ClO}_{4}{ }^{-}\right)$and $\mathbf{2}\left(\mathrm{NO}_{3}{ }^{-}\right)$, as compared to other two compounds (Table 3 ). The results of all studies corroborate well with the findings of fluorescence and UV studies.

3.5. Molecular Docking. To provide further and deeper insight into the interactions of HSA with compounds $\mathbf{1}$ and $\mathbf{2}$, a molecular docking technique was employed to learn more about the exact binding sites inside the molecular target HSA. From the $3 \mathrm{D}$ structure of crystalline albumin, it is known that HSA comprises three homologous domains that assemble to form a heart-shaped molecule, denoted I, II, and III: I (residues 1-195), II (196-383), and III (384-585). The principal region of compound $\mathbf{1}$ binding sites of HSA is located in hydrophobic cavities in the subdomains IIA and IIIA, corresponding to sites I and II, respectively, and the tryptophan residue (Trp-214) of HSA in the subdomain IIA. A large hydrophobic cavity in the subdomain IIA (a binding site at I) to accommodate compound $\mathbf{1}$ is present, while compound $\mathbf{2}$ preferentially appears to the bind at site III. The minimum energy docked pattern (Figure 9(a)) indicates that compound 1 is primarily located within the subdomain IIA of HSA, forming numerous hydrophobic contacts $(\pi-\sigma, \pi-\pi$ stacked, and $\pi$-alkyl) with GLN196, HIS242, LYS199, LYS195, CYS200, CYS245, and CYS245 residues of the hydrophobic binding site IIA (Figure 10(a)). Furthermore, also a number of hydrogen bonds and specific electrostatic interaction formed by the compound $\mathbf{1}$ are observed (Table 4 ).

The resulting docked pattern (Figure 9(b)) indicates that compound $\mathbf{2}$ is located in the subdomains IA and IB, forming various noncovalent interactions like hydrogen bond, electrostatic, and hydrophobic within the binding cavity residues. A detailed description is given in Table 5 (Figure 10(b)). These noncovalent interactions formed by both the compounds $\mathbf{1}$ and $\mathbf{2}$ are dominated by hydrophobic contacts, with additional stabilization also assisted by the hydrogen bonding and electrostatic interaction with the polar residues of the binding site cavity. It has been previously observed [46, 47] that hydrogen bonding and electrostatic interaction decreased the hydrophilicity and increased the hydrophobicity to keep the compounds-HSA system stable. The relative binding energy of the docked structures was found to be -344.74 and $-326.31 \mathrm{~kJ} / \mathrm{mol}$ for $\mathbf{1}$ and $\mathbf{2}$, respectively. The results obtained from the molecular docking studies revealed that the hydrophobic forces dominated the interaction of Ag compounds with the HSA. Notably, the binding of the compounds 1 and 2 to different sites can be largely associated with the difference of ionic sphere.

To find out the effect of counterion in the HSA binding, we also perform the docking of the individual counterion
TABLE 3: Effect of the Ag(I) compounds on the $\alpha$-helical structure of HSA (model protein) expressed as percentage $\alpha$-helix character.

\begin{tabular}{lcccc}
\hline \multirow{2}{*}{ Concentration $(\mathrm{mM})$} & \multicolumn{4}{c}{$\%$-helix } \\
& $\mathbf{1}\left(\mathrm{ClO}_{4}^{-}\right)$ & $\mathbf{2}\left(\mathrm{NO}_{3}{ }^{-}\right)$ & $\mathbf{3}\left(\mathrm{PF}_{6}{ }^{-}\right)$ & $\mathbf{4}\left(\mathrm{BF}_{4}^{-}\right)$ \\
\hline 0 & 67.03 & 67.03 & 67.03 & 67.03 \\
20 & 64.07 & 62.85 & 63.57 & 65.25 \\
40 & 62.23 & 61.61 & 62.57 & 63.82 \\
60 & 58.59 & 58.41 & 60.37 & 61.53 \\
80 & 50.18 & 52.02 & 56.31 & 56.66 \\
100 & 35.63 & 42.73 & 47.18 & 47.52 \\
\hline
\end{tabular}

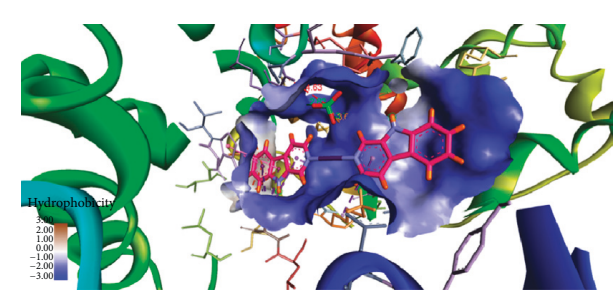

(a)

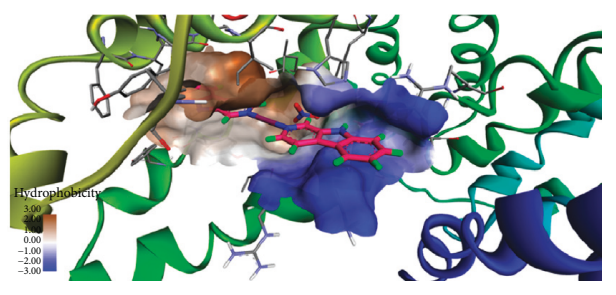

(b)

FIgURE 9: (a) Molecular docked model of compound 1 (stick representation) located within the hydrophobic pocket in the subdomain IIA of HSA; (b) molecular docked model of compound 2 (stick representation) located within the hydrophobic pocket in the subdomain IB of HSA.

(nitrate ion and perchlorate ion) with the HSA (Figure S9). In the minimum energy docked pose, the nitrate and perchlorate ion are found in the outer environment of the binding site's IIA and IIIA domains, respectively. These anions form electrostatic and other noncovalent interaction at these domains, which could be responsible for the microenvironmental changes or conformational changes of proteins. So that presence of the nitrate and perchlorate ions in the complex may have facilitated or enhanced the binding propensity (see Tables S1 and S2 in Supplementary Materials), which is also evident from the binding constant values in the presence of the anions. Thus, it plays an influential role in binding to the biomolecule. This observation confirms the significant role of the anions in the mode of interaction with the biomolecule.

\section{Concluding Remarks}

$\beta$-Carbolines motif crosses blood-brain membrane (BBM) and are known to inhibit the phosphorylated form of the tau protein [9]. These inhibitions are the essential features to study for any new compound to treat diseases such as Alzheimer's disease. Spectrophotometric methods have been 


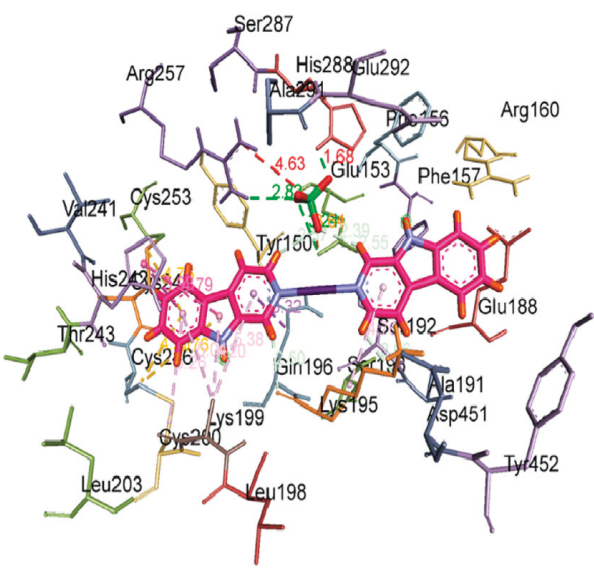

(a)

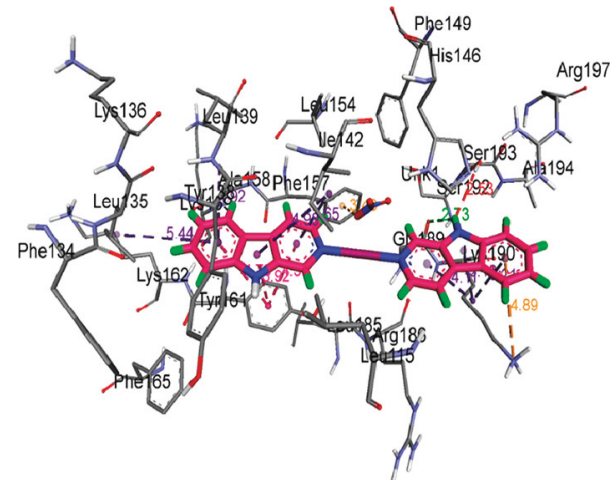

(b)

FIgURE 10: Noncovalent interactions of compounds (a) 1 and (b) 2 at the subdomains IIA and IB of HSA, respectively.

TABLE 4: Noncovalent interactions of compound 1 with the HSA binding site IIA.

\begin{tabular}{lccc}
\hline Name & Distance $(\AA)$ & Category & Type \\
\hline ARG257: H11-Complex 1: O1' & 2.81 & & Hydrogen bond \\
HIS288: H1-compound 1: O3 & 1.68 & & Conventional \\
Compound 1: O1'-GLU153: O1 & 3.24 & Electrostatic & Attractive charge \\
Compound 1: Cl1-GLU153: O1 & 3.63 & & $\pi$-Sigma \\
GLN196-compound 1 & 3.32 & & $\pi$ Stacked \\
HIS242-compound 1 & 4.78 & & $\pi$ - $\pi$ Stacked \\
HIS242-compound 1 & 3.92 & & $\pi$-Alkyl \\
Compound 1-LYS199 & 5.38 & Hydrophobic & $\pi$-Alkyl \\
Compound 1-LYS199 & 4.19 & & $\pi$-Alkyl \\
Compound 1-LYS195 & 4.75 & & $\pi$-Alkyl \\
Compound 1-LYS199 & 5.03 & $\pi$-Alkyl \\
Compound 1-CYS200 & 5.25 & & $\pi$-Alkyl \\
Compound 1-CYS245 & 4.23 & & $\pi$-Alkyl \\
Compound 1-CYS246 & 4.92 & & \\
\hline
\end{tabular}

TABle 5: Noncovalent interactions of compound 2 with the HSA binding site III.

\begin{tabular}{lccc}
\hline Name & Distance $(\AA)$ & Category & Type \\
\hline Compound 2: H4-GLY189:O & 2.73 & Hydrogen bond & Conventional \\
LYS190-compound 2 & 4.88 & Electrostatic & $\pi$-Cation \\
Compound 2: O3-PHE157 & 3.39 & Electrostatic & $\pi$-Anion \\
TYR161-compound 2 & 4.29 & & $\pi$ - Stacked \\
TYR161-compound 2 & 4.72 & & $\pi$ - Stacked \\
Compound 2-A: TYR161 & 3.91 & & $\pi$ - $\pi$ Stacked \\
Compound 2-A: ILE142 & 3.64 & Hydrophobic & $\pi$-Alkyl \\
Compound 2-A: ILE142 & 4.98 & & $\pi$-Alkyl \\
Compound 2-A: LEU135 & 5.43 & & $\pi$-Alkyl \\
Compound 2-A: ALA158 & 4.91 & & $\pi$-Alkyl \\
Compound 2-A: LYS190 & 4.11 & & $\pi$-Alkyl \\
Compound 2-A: LYS190 & 3.09 & & $\pi$-Alkyl \\
Compound 2-A: LYS190 & 3.21 & & $\pi$-Alkyl \\
\hline
\end{tabular}

used to investigate the interaction between HSA and the present $\operatorname{Ag}(\mathrm{I})$ compounds. All Ag(I) compounds showed a strong affinity towards HSA. An extra effect of the perchlorate and nitrate anions was found in the binding studies, which ascertained the higher binding propensity of the $\mathrm{Ag}(\mathrm{I})$ compounds with counteranions $\mathrm{ClO}_{4}{ }^{-}$and $\mathrm{NO}_{3}{ }^{-}$. The moderate $\mathrm{HSA}$ binding in the case of $\mathrm{BF}_{4}{ }^{-}$and $\mathrm{PF}_{6}{ }^{-}$salts could be enhanced by the addition of extra anions, namely, $\mathrm{ClO}_{4}{ }^{-}$and $\mathrm{NO}_{3}{ }^{-}$. The results have shown a significant role of the anion in Ag-HSA binding and even showed an exponential increase in the binding propensity of the $\operatorname{Ag}(\mathrm{I})$ compounds. This affinity has been attributed to the increased exposure of the Ag-binding subdomains of HSA, as a result of the electrostatic and hydrophobic interactions. The 
presence of Hnor, despite being a labile ligand, appears to be important for the binding to HSA. The effect of anions was further validated by the molecular modeling studies which corroborate well with our findings of binding studies and ascertain that anions play an importance role in binding to HSA.

\author{
Abbreviations \\ HSA: Human serum albumin \\ CD: Circular dichroism \\ Cys: Cysteine \\ Met: Methionine \\ Hnor: 9H-pyrido[3,4-b]indole (norharmane).
}

\section{Conflicts of Interest}

The authors declare that there are no conflicts of interest.

\section{Authors' Contributions}

Ali Alsalme and Rais Ahmad Khan contributed equally to this work.

\section{Acknowledgments}

The authors extend their appreciation to the Deanship of Scientific Research at King Saud University for funding this work through the research group number RG-1438-006.

\section{Supplementary Materials}

Figure S1: UV absorption spectra of HSA in the absence and presence of compounds 1-4; concentration [HSA] $=5 \mu \mathrm{M}$. Figure S2: UV absorption difference of HSA (the difference UV absorption spectra were obtained by HSA-Ag compound spectra minus Ag compound spectra). Figure S3: fluorescence emission spectra of HSA $(5 \mu \mathrm{M})$ in the presence of various concentrations of compounds 2, 3, and 4; curves from 1 to 10 correspond to compound concentrations of 0 , $0.5,1,1.5,2,3,4,5,7.5$, and $10 \mu \mathrm{M}$, respectively, when excited at $295 \mathrm{~nm}$. Figure S4: the Stern-Volmer plot for the quenching of the HSA fluorescence by compounds 2, 3, and 4 at $295 \mathrm{~nm}$. Inset: plot of $\log \left(F_{0}-F\right) / F$ as a function of $\log$ (complex). Figure S5: fluorescence emission spectra of HSA $(5 \mu \mathrm{M})$ in the presence of various concentrations of compounds 1-4, corresponding to compound concentrations of $0,1,2,4,7.5$, and $10 \mu \mathrm{M}$ with the addition of extra $\mathrm{KClO}_{4}$ in a $1: 4$ ratio, respectively, when excited at $295 \mathrm{~nm}$. Figure S6: fluorescence emission spectra of HSA $(5 \mu \mathrm{M})$ in the presence of various concentrations of compounds 1-4, corresponding to compound concentrations of $0,1,2,4,7.5$, and $10 \mu \mathrm{M}$ with the addition of extra $\mathrm{KNO}_{3}$ in $1: 4$ ratio, respectively, when excited at $295 \mathrm{~nm}$. Figure S7: CD spectra of the HSA-compound system (HSA $=20 \mu \mathrm{M}$ ) in the presence of various concentrations of compounds 2, 3, and 4; curves from 1 to 6 corresponding to compound concentrations of $0,20,40,60,80$, and $100 \mathrm{mM}$, respectively. Figure S8: absorption spectra of Ag complexes only, 1: $\mathrm{ClO}_{4}$ (red line) and 2: $\mathrm{NO}_{3}$ (black line) of $1.0 \mathrm{mM}$ solution. Figure $\mathrm{S} 9$ : molecular docked model of HSA in presence of anions. Table S1: noncovalent interactions of nitrate ion with the HSA. Table S2: noncovalent interactions of perchlorate ion with the HSA. (Supplementary Materials)

\section{References}

[1] M. C. Gimeno and A. Laguna, Comprehensive Coordination Chemistry II, J. A. McCleverty and T. J. Meyer, Eds., vol. 6, Elsevier Pergamon, Oxford, UK, 2nd edition, 2004.

[2] A. N. Khlobystov, A. J. Blake, N. R. Champness et al., "Supramolecular design of one-dimensional coordination polymers based on silver(I) complexes of aromatic nitrogen-donor ligands," Coordination Chemistry Reviews, vol. 222, pp. 155192, 2001.

[3] A. B. G. Lansdown, Silver in Healthcare: Its Antimicrobial Efficacy and Safety in Use, Royal Society of Chemistry, London, UK, 2010.

[4] N. Farrell, Comprehensive Coordination Chemistry, J. A. McCleverty and T. J. Meyer, Eds., vol. 9, Elsevier Pergamon, Oxford, UK, 2nd edition, 2004.

[5] K. M. Fromm, "Give silver a shine," Nature Chemistry, vol. 3, p. 178, 2011.

[6] M. Rai, A. Yadav, and A. Gade, "Silver nanoparticles as a new generation of antimicrobials," Biotechnology Advances, vol. 27, no. 1, pp. 76-83, 2009.

[7] J. L. Clement and P. S. Jarret, "Antibacterial silver," MetalBased Drugs, vol. 1, no. 5-6, pp. 467-482, 1994.

[8] S. Ray, R. Mohan, J. K. Singh et al., "Anticancer and antimicrobial metallopharmaceutical agents based on palladium, gold, and silver N-Heterocyclic carbene complexes," Journal of the American Chemical Society, vol. 129, no. 48, pp. 15042-15053, 2007.

[9] S. Medici, M. Peana, V. M. Nurchi, J. I. Lackowicz, G. Crisponi, and M. A. Zoroddu, "Noble metals in medicine: latest advance," Coordination Chemistry Reviews, vol. 284, pp. 329-350, 2015.

[10] S. Eckhardt, P. S. Brunetto, J. Gagnon, M. Priebe, B. Giese, and K. M. Fromm, "Nanobio silver: its interactions with peptides and bacteria, and its uses in medicine," Chemical Reviews, vol. 113, no. 7, pp. 4708-4754, 2013.

[11] V. Gandin, M. Pellei, M. Marinelli et al., "Synthesis and in vitro antitumor activity of water soluble sulfonate- and esterfunctionalized silver(I) N-heterocyclic carbene complexes," Journal of Inorganic Biochemistry, vol. 129, pp. 135-144, 2013.

[12] D. C. Carter and J. X. Ho, "Structure of serum albumin," Advances in Protein Chemistry, vol. 45, pp. 153-203, 1994.

[13] R. E. Olson and D. D. Christ, "Chapter 33 plasma protein binding of drugs," Annual Reports in Medicinal Chemistry, vol. 31, pp. 327-337, 1996.

[14] T. Peters Jr., All about Albumin: Biochemistry, Genetics and Medical Applications, Academic Press, Cambridge, MA, USA, 1996.

[15] T. Peters Jr., "Serum albumin," Advances in Protein Chemistry, vol. 37, pp. 161-245, 1985.

[16] U. Anand and S. Mukherjee, "Binding, unfolding and refolding dynamics of serum albumin," Biochimica et Biophysica Acta, vol. 1830, pp. 5394-5404, 2013.

[17] M. Vignoni, F. A. O. Rasse-Suriani, K. Butzbach, R. ErraBalsells, B. Epe, and F. M. Cabrerizo, "Mechanisms of DNA damage by photoexcited 9-methyl- $\beta$-carbolines," Organic \& Biomolecular Chemistry, vol. 11, no. 32, pp. 5300-5309, 2013.

[18] M. A. Collins and E. J. Neafsey, Neurotoxic Factors in Parkinson's Disease and Related Disorders, A. Storch and 
M. A. Collins, Eds., Kluwer Academic/Plenum Publishers, New York, NY, USA, 2000.

[19] J. Hamann, C. Wernicke, J. Lehmann, H. Reichmann, H. Rommelspacher, and G. Gille, "9-Methyl- $\beta$-carboline up-regulates the appearance of differentiated dopaminergic neurones in primary mesencephalic culture," Neurochemistry International, vol. 52, no. 4-5, pp. 688-700, 2008.

[20] D. Frost, B. Meechoovet, T. Wang et al., " $\beta$-Carboline compounds, including harmine, inhibit DYRK1A and tau phosphorylation at multiple Alzheimer's disease-related sites," PLoS One, vol. 6, no. 5, article e19264, 2011.

[21] R. A. Khan, K. Al-Farhan, A. de Almeida et al., "Light-stable bis(norharmane)silver(I) compounds: synthesis, characterization and antiproliferative effects in cancer cells," Journal of Inorganic Biochemistry, vol. 140, pp. 1-5, 2014.

[22] D. Mustard and D. W. Ritchie, "Docking essential dynamics eigenstructures," Proteins: Structure, Function, and Bioinformatics, vol. 60, no. 2, pp. 269-274, 2005.

[23] D. W. Ritchie and V. Venkatraman, "Ultra-fast FFT protein docking on graphics processors," Bioinformatics, vol. 26, no. 19, pp. 2398-2405, 2010.

[24] Accelrys Software Inc., Discovery Studio Modeling Environment, Release 4.0, Accelrys Software Inc., San Diego, CA, USA, 2013.

[25] The PyMOL Molecular Graphics System, Version 1.5.0.4, Schrödinger LLC, New York, NY, USA, 2013.

[26] Y. Hatanaka and Y. Sadakane, "Photoaffinity labeling in drug discovery and developments: chemical gateway for entering proteomic frontier," Current Topics in Medicinal Chemistry, vol. 2, no. 3, pp. 271-288, 2002.

[27] D. Robinette, N. Neamati, K. B. Tomer, and C. H Borchers, "Photoaffinity labeling combined with mass spectrometric approaches as a tool for structural proteomics," Expert Review of Proteomics, vol. 3, no. 4, pp. 399-408, 2006.

[28] H. Mach, D. B. Volkin, C. J. Burke, and C. R. Middaugh, "Ultraviolet absorption spectroscopy," in Protein Stability and Folding: Theory and Practice, Methods in Molecular Biology, B. A. Shirley, Ed., vol. 40, Humana Press, Totowa, NJ, USA, 1995.

[29] V. Chabert, M. Hologne, O. Sénèque, A. Crochet, O. Walker, and K. M. Fromm, "Model peptide studies of Ag+ binding sites from the silver resistance protein SilE," Chemical Communications, vol. 53, no. 45, pp. 6105-6108, 2017.

[30] S. Kracht, M. Messerer, M. Lang et al., "Electron transfer in peptides: on the formation of silver nanoparticles," Angewandte Chemie International Edition, vol. 54, no. 10, pp. 2912-2916, 2015.

[31] X.-C. Shen, H. Liang, J.-H. Guo, C. Song, X.-W. He, and Y.-Z. Yuan, "Studies on the interaction between Ag+ and human serum albumin," Journal of Inorganic Biochemistry, vol. 95, no. 2-3, pp. 124-130, 2003.

[32] V. D. Suryawanshi, P. V. Anbhule, A. H. Gore, S. R. Patil, and G. B. Kolekar, "Photoaffinity labeling combined with mass spectrometric approaches as a tool for structural proteomics," Journal of Photochemistry and Photobiology B: Biology, vol. 118, pp. 1-8, 2013.

[33] S. Tabassum, M. Zaki, M. Ahmad et al., "Synthesis and crystal structure determination of copper(II)-complex: in vitro DNA and HSA binding, pBR322 plasmid cleavage, cell imaging and cytotoxic studies," European Journal of Medicinal Chemistry, vol. 83, pp. 141-154, 2014.

[34] S. Tabassum, W. M. Al-Asbahy, M. Afzal, F. Arjmand, and R. H. Khan, "Interaction and photo-induced cleavage studies of a copper based chemotherapeutic drug with human serum albumin: spectroscopic and molecular docking study," Molecular BioSystems, vol. 8, no. 9, pp. 2424-2433, 2012.

[35] C. A. Royer and B. A. Shsirley, Protein Stability, and Folding: Theory and Practice, Methods in Molecular Biology, vol. 40, Humana Press, Totowa, NJ, USA, 1995.

[36] J. R. Lackowicz, Principles of Fluorescence Spectroscopy, Plenum Press, New York, NY, USA, 2nd edition, 1999.

[37] D. Romanini, G. Avalle, B. Farruggia, B. Nerli, and G. Pico, "Spectroscopy features of the binding of polyene antibiotics to human serum albumin," Chemico-Biological Interactions, vol. 115 , no. 3, pp. 247-260, 1998.

[38] M. R. Eftink and T. G. Dewey, Biophysical and Biochemical Aspects of Fluorescence Spectroscopy, Plenum Press, New York, NY, USA, 1991.

[39] W. R. Ware, "Oxygen quenching of fluorescence in solution: an experimental study of the diffusion process," Journal of Physical Chemistry, vol. 66, no. 3, pp. 455-458, 1962.

[40] M. S. Ali and H. A. Al-Lohedan, "Interaction of human serum albumin with sulfadiazine," Journal of Molecular Liquids, vol. 197, pp. 124-130, 2014.

[41] D.M. Togashi, A.G. Ryder, and J. Fluoresc, "A fluorescence analysis of ANS bound to bovine serum albumin: binding properties revisited by using energy transfer," Journal of Fluorescence, vol. 18, no. 2, pp. 519-526, 2008.

[42] O. Stern and M. Volmer, "Über die abklingzeit der fluoreszenz," Physikalische Zeitschrift, vol. 20, pp. 183-188, 1919.

[43] Y. H. Chen, J. T. Yang, and H. M. Martinez, "Determination of the secondary structures of proteins by circular dichroism and optical rotatory dispersion," Biochemistry, vol. 11, no. 22, pp. 4120-4131, 1972.

[44] M. T. Rehman, H. Shamsi, and A. U. Khan, "Insight into the binding mechanism of imipenem to human serum albumin by spectroscopic and computational approaches," Molecular Pharmaceutics, vol. 11, no. 6, pp. 1785-1797, 2014.

[45] M. T. Rehman, S. Ahmed, and A. U. Khan, "Interaction of meropenem with " $\mathrm{N}$ " and " $\mathrm{B}$ " isoforms of human serum albumin: a spectroscopic and molecular docking study," Journal of Biomolecular Structure and Dynamics, vol. 34, no. 9, pp. 1894-1864, 2015.

[46] S. Tabassum, W. M. Al-Asbahy, M. Afzal, and F. Arjmand, "Synthesis, characterization and interaction studies of copper based drug with Human Serum Albumin (HSA): spectroscopic and molecular docking investigations," Journal of Photochemistry and Photobiology B: Biology, vol. 114, pp. 132-139, 2012.

[47] Y. Shua, W. Xueb, X. Xua et al., "Interaction of erucic acid with bovine serum albumin using a multi-spectroscopic method and molecular docking technique," Food Chemistry, vol. 173, pp. 31-37, 2015. 

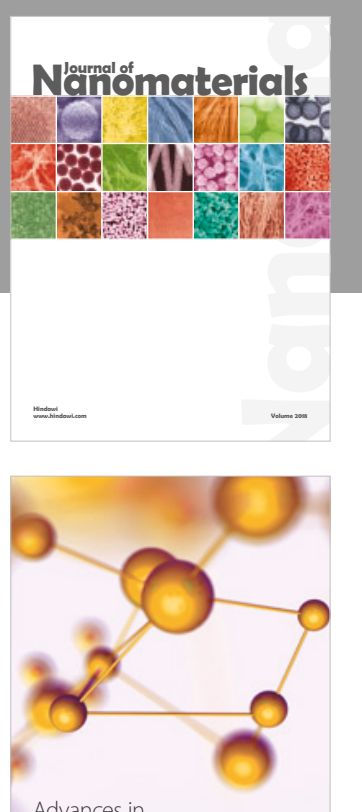

Physical Chemistry
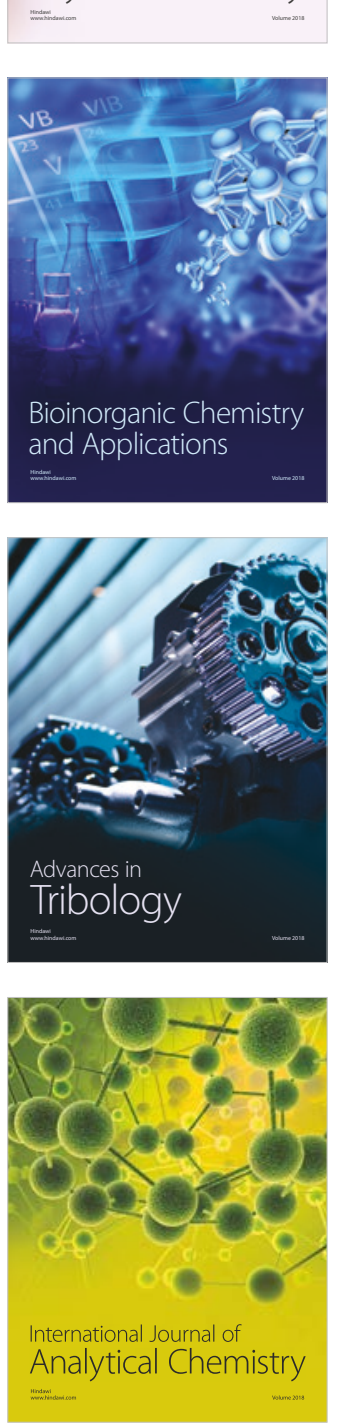

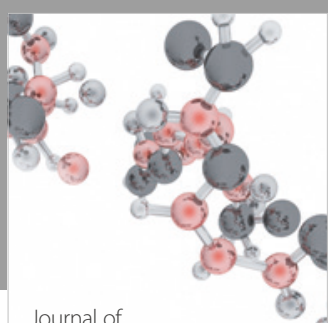

Analytical Methods

in Chemistry

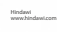

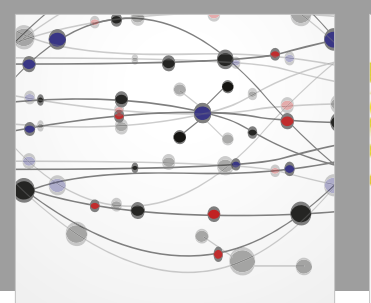

The Scientific World Journal

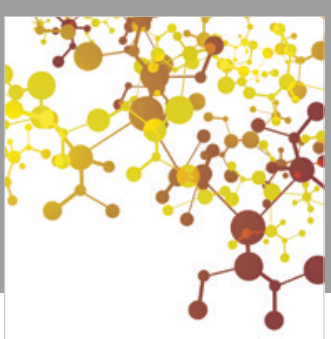

Journal of

Applied Chemistry
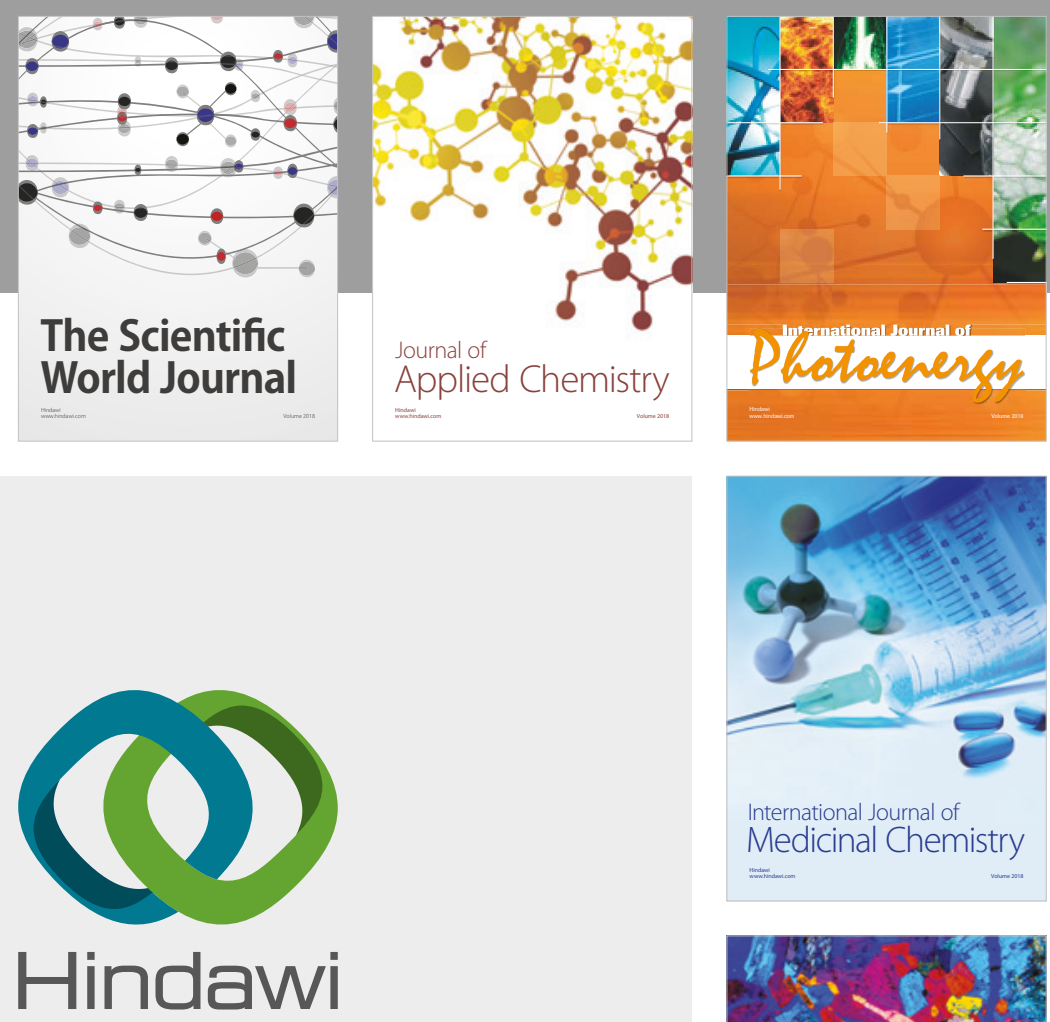

Submit your manuscripts at

www.hindawi.com
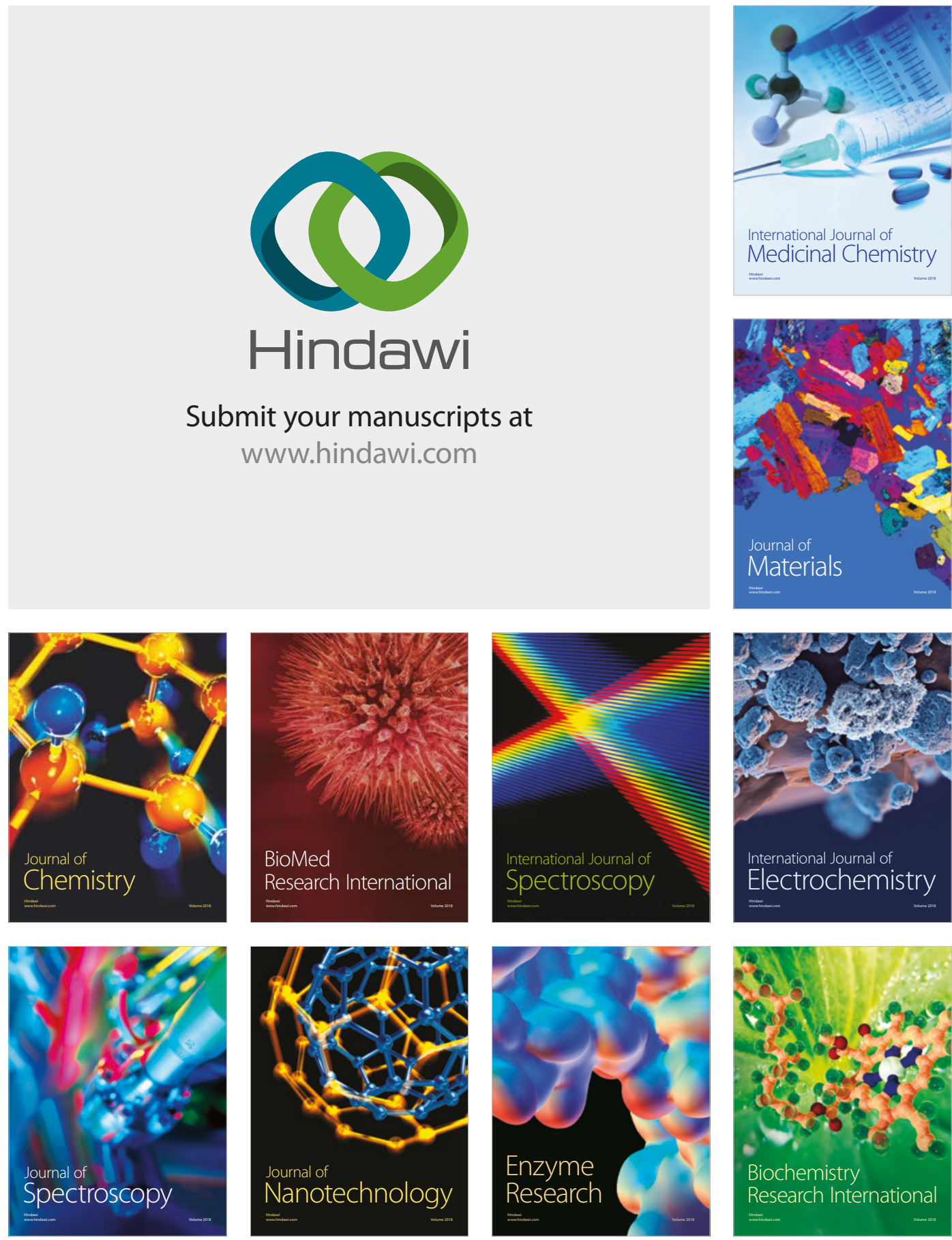
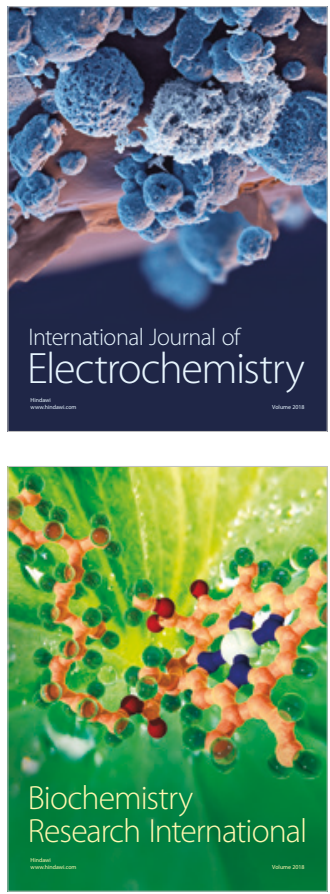